\title{
Their capital has value, too: Exploring parental educational support in low-socioeconomic single-mother families
}

\section{Carmelita Jacobs}

Department of Educational Psychology, Faculty of Education, Stellenbosch University, Stellenbosch, South Africa carmelitaj32@sun.ac.za https://orcid.org/0000-0001-6344-1522

\section{Doria Daniels}

Department of Educational Psychology, Faculty of Education, Stellenbosch University, Stellenbosch, South Africa

doria@sun.ac.za

https://orcid.org/0000-0003-0522-1980

(Received: 21 January 2020; accepted: 15 September 2020)

\section{Abstract}

Parental educational support is a key contributing factor to the educational success of children (Epstein, 2018; Hill \& Tyson, 2009; Seginer, 2006). However, educational research has shown that schools tend to engage with single-mother families from a deficit perspective, labelling such parents "uninvolved" and "uncaring" (Hampden-Thompson, 2009; Hoover-Dempsey et al., 2001; Robinson \& Werblow, 2012). Often not considered, are the embedded forms of capital present in single-parent families and the ways in which single parents invest in their children's education. In this article, we report on the findings of a qualitative multiple-case study of single-mother families from a South African community. Six single-mother family units were researched for the contributions they made to their children's educational success. Our theoretical framework was informed by Yosso's (2005) model of community cultural wealth. Our findings show that, despite severe societal adversity, these participating mothers invested in their children's educational and emotional well-being by accumulating alternative forms of embedded community cultural wealth. Our findings have relevance for the ways in which schools engage with, and collaborate with, such parent communities to advance positive school-family relationships.

Keywords: parental educational support, parental engagement, single-mother families, community cultural wealth 


\section{Introduction}

Parents play an essential role in the education of their children, and their involvement is considered by educationists to be an important predictor of children's school success (Epstein, 2018; Hoover-Dempsey \& Sandler, 1997; Jeynes, 2011; Kaplan Toren, 2013; Seginer, 2006). Many of the world's children are being raised in one-parent households, mostly female headed (Budlender \& Lund, 2011). Society might want us to believe that single mothers do not have a road map to educational success for their children because of a biased perception that one-parent families lack the necessary educational and material resources to support their children's education. In Bourdieusian (2007) terms, such homes are assumed to have limited inherited cultural capital. We argue that such perceptions are perpetuated by educational research that has engaged with parent involvement and support in very specific ways: as financial support of their children's education, as supporter of schoolrelated activities (Lemmer, 2007), and as representation on school governing bodies (Mncube, 2009). When parents fail to measure up to these "legitimised" forms of support, they are deemed to be uninvolved and unsupportive parents. This very narrow view of the contributions that parents make to the academic success of their children eliminates other informal and less recognised contributions, that especially marginalised parents make, as being valuable and worthy.

Most international research on parent support has had the middle-class family as context, and used the two-parent family as norm when researching parent involvement (Epstein, 2011; Hoover-Demsey et al., 2001; LeFevre \& Shaw, 2005). As a result, the educational support experiences of parents from low-socioeconomic communities remain underreported, and knowledge about how these parents navigate and contribute to their children's educational success remains under explored. We argue that there are sociocultural differences in parents' educational support strategies, and that family structures impose differing challenges on parents' contributions (Camacho-Thompson et al., 2019; Daniels, 2017, 2018; Epstein, 2011; Hoover-Demsey et al., 2001; LeFevre \& Shaw, 2005; Okeke, 2014). For our discussion, we limit our context to the single-mother family unit.

Although an estimated $70 \%$ of South Africa's children grow up in single-parent households (Budlender \& Lund, 2011), the parent support literature has seen such families as the exception rather than the norm. Both national and international educational research has adopted a deficit approach to such families' ability to be a supportive educational environment (Aragon, 2018; Baquendano-Lopez et al., 2013; Koh et al., 2017; Newlin, 2017). These families have been described as broken, incomplete family units and presumed to be educationally disadvantaged (Gagnon, 2018; Hampden-Thompson, 2009; HampdenThompson \& Galindo, 2015; Knowles \& Holmström, 2013; Musick \& Meier, 2010). They have been presumed to be at high risk due to financial and social pressures, and the parents expected to be less involved in their children's schooling (Hampden-Thompson, 2009; Knowles \& Holmström, 2013; Musick \& Meier, 2010). Our research goal is to disrupt this stereotypical perception of female-headed households as being incomplete and dysfunctional units. By telling the stories of how six single-mother families invested in the educational 
success of their adolescent high school children, we provide opportunities for society to see the investment these parents made in their children's educational success.

Studies that used positive, asset-based approaches in their interactions with Latino and African-American single-mother families have shown how parents provided educational support to their children in informal and nontraditional ways (Camacho-Thompson et al., 2019; Lopez et al., 2001; Robinson \& Werblow, 2012; Vega et al., 2015; Williams \& Sánchez, 2012). Our work was informed by feminist learnings, and our goal was to capture both the complexities and the resiliencies embedded in single-mother households.

\section{Parent involvement, parent engagement, and parental educational support}

In this article, we use the term, parental educational support, to refer to all those activities and practices at home or school that promote academic and social outcomes (Epstein, 2011, 2018; Hill \& Tyson, 2009; Seginer, 2006). Our understanding of parental educational support is that it is a complex and multidimensional concept, which is influenced by factors such as race, class, socioeconomic status, history, and context. We acknowledge that parents from different ethnic, cultural, or racial backgrounds might use different support strategies (Bhargava \& Witherspoon, 2015; Hill \& Tyson, 2009), some of which may not be accepted as educational support. Furthermore, the socioeconomic status (SES) of families could impact on the educational support that parents are able to provide and the effectiveness of that support (Bhargava \& Witherspoon, 2015; Rawatlal et al., 2015; Wang \& Sheikh-Khalil, 2014). Research has shown that parents with a higher SES engage in more parental involvement, and that parents with a low SES engage in less home-based and school-based support-often because of limited material and social resources (Wang \& Sheikh-Khalil, 2014). Such research, however, has mostly used middle-class two-parent families as norm, and shown families that do not fit that as being uninvolved and deficit in their support and involvement. Our view is that traditional views of parents' educational support are not universally applicable and a broader conceptualisation of parental educational support is needed.

Our understanding of parental educational support is more inclusive and broader than schools' understandings, which only link certain parent activities to educational success, namely, homework support, physical presence at children's extramural activities, and participation at meetings and school functions (Green et al., 2007). Our stance is situated in a positive, asset-based approach to parents' involvement and support. We do not limit parents' educational support to school-sanctioned activities only. Our parent support research interests include academic socialisation, which is a more informal strategy that involves communication by parents of their expectations of and aspirations for their children, and its potential to advance strong positive relationships and educational success in high school learners (Toren \& Seginer, 2015; Wang \& Sheikh-Khalil, 2014).

Yosso's (2005) research in disadvantaged communities has made her advocate for the legitimisation and recognition by society of the cultural wealth present in such communities 
and its role in children's educational success. Her theory of community cultural wealth has challenged researchers to discover the alternative or supplementary cultural and social culture present in poor families. By applying Yosso's theory of community cultural wealth as our theoretical framework, we created the space to develop alternative understandings of parents' investments in their children's educational success. Community cultural wealth refers to the "knowledge, skills, abilities and relationships" that exist in families (Yosso, 2005, p. 76). Yosso (2005) identified several forms of capital that socially, economically, and linguistically disadvantaged families can accumulate, namely aspirational, linguistic, familial, navigational, and resistant capitals. She explained how disadvantaged communities acquire alternative forms of capital such as skills, abilities, resources, and knowledges that a network of people builds up over time. She described aspirational capital as the ability to maintain a sense of hope in the midst of adversity. Children from immigrant communities acquire linguistic capital to serve as brokers of communication for their parents. Significant relationships with community members often contribute to the accumulation of familial capital. And, through these relationships, special knowledge or navigational capital can be acquired, which, in turn, can assist children in navigating systems or institutions. Yosso (2005) described resistant capital as the skills that individuals develop to assist them in challenging systems of inequality or in resisting their status in life. Cultural resources such as family and community members can be utilised to access opportunities such as education. Community cultural wealth can therefore be mobilised as active family resources. She further maintained that the "various forms of capital are not mutually exclusive or static, but rather are dynamic processes that build on one another as part of community cultural wealth" (Yosso, 2005, p. 77).

Community cultural wealth theory is the analytical lens through which we interpreted how single mothers from low socioeconomic backgrounds supported their adolescent high school children's educational journeys. For this article, we drew on the data of a doctoral study (Jacobs, 2019) that explored the opportunities and potentialities for educational support in six single-parent, female-headed families. We explored the capital present in these families and the acts of agency from family role-players. The question the article responds to is: "What are the ways in which single mothers provide educational support to their adolescent children?"

\section{Method and methodology: Positioning the mother in the community}

The aim of the research was to uncover the views, beliefs, and experiences of single-mother households about parental educational support to their children. Following the qualitative research tradition, we studied six families living in Indigo Town, a low socioeconomic, traditionally Afrikaans-speaking, coloured community in the Western Cape province of South Africa. Two community workers served as go-between and introduced us to several potential participants. From those families, six were purposively selected according to the following inclusion criteria: (a) The family unit had to be headed by a single mother, (b) the family unit 
had to include an adolescent who was in high school, and (c) the adolescent had to have been raised by a single mother for most of their life.

This multiple case study was grounded in a social constructivist paradigm and had as purpose to understand the subjective meaning making of the participants in their real-world contexts (Merriam, 2009). According to Patton (2002), it is the quality of the insights generated that is important and not necessarily the quantity of insights. Our data collection methods involved individual, semi-structured interviews with the parent and adolescent, as well as a focus group discussion with the adolescents. Ethical clearance for the project was granted by our institution, and informed consent was negotiated through explaining the aims and goals of the study to the participants, as well as what was expected of them should they decide to participate. Our decisions and actions were guided by our ethical concerns about the vulnerability of the research population and respect for their rights. Because the home context and home circumstances were considered important influences on the parents' decisions, we sought their permission to access their home environments and contextualise their experiences. The data were analysed using thematic content analysis. Atlas.ti was used as a tool to code transcripts and field notes and to identify themes in the data (Creswell, 2007). In Figure 1, we visually plot the six family units and their family members.

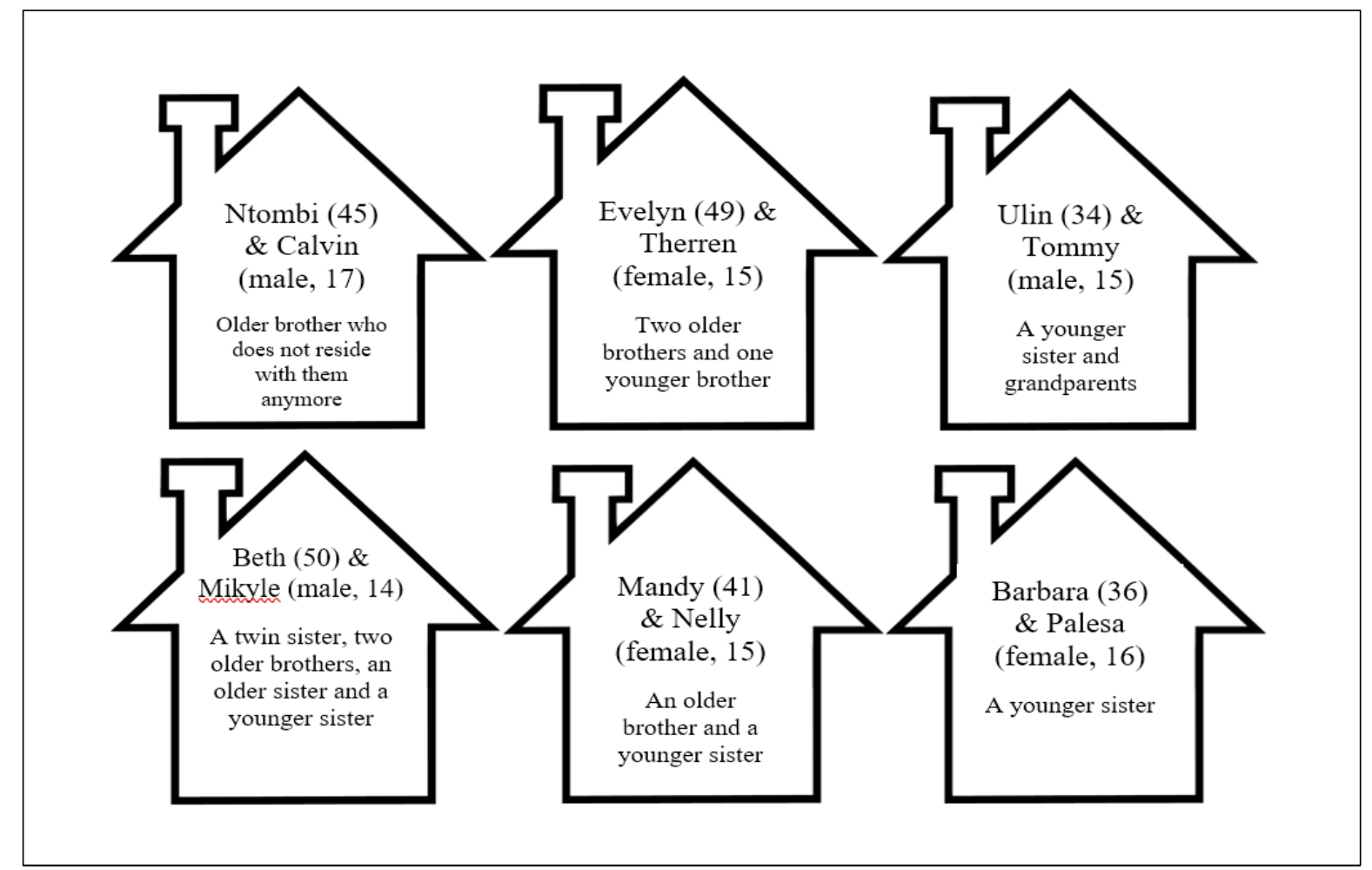

Figure 1: The six family units

In this community, most residents own their own homes because the South African government, after 1994, transferred the title deeds of township homes to the rent paying occupants. Three of the participating women were homeowners. Although most of the residents experienced socioeconomic challenges, there seemed to be a nuanced divide based on whether they lived in the "better" parts or in the "poorer," "more dangerous" areas of the community. To live in the better part of the township meant you lived in the quieter area 
where fewer incidents of shooting and gang violence were reported. Two of the families lived in the dangerous part of Indigo Town and the other four families lived in the quieter part of the community.

\section{Findings: "Having a road map for educational success for my child to follow"}

Although all six mothers had completed their basic formal education, they, on average, had only completed one year of high school education. Most of the mothers were unemployed and lived off their state welfare grants. Ntombi and Ulin were employed as blue-collar workers. With the exception of Mandy, none received financial support from the fathers of their children. In their frustration about their situational challenges, the women often reverted to a patriarchal understanding of family roles in their conversations with us. Despite being the sole caregivers of their children and their experience with absentee partners, they still seemed to believe that a male partner would change their home situations for the better. Given their circumstances, one could easily conclude that these parents did not have a road map for the educational success of their high school children. However, our analysis of the data highlighted several ways in which the mothers actively worked towards creating and sustaining opportunities for their adolescents' educational success. In what follows, we present the ways in which these parents navigated their challenges in proactive ways.

\section{"I don't want my story to become my child's": Rewriting the narrative of disadvantage and discontent}

In our interviews with the mothers, we gained insight into how their own interrupted schooling had shaped their views of education and the importance of their children's education. We found that the mothers used their own history with schooling to inspire their children to value education and to work hard to reap the benefits that could come from education. For example, Beth left school in Grade 7 to become a farm worker like her parents. Although she earned a meagre R12.50 as weekly wage then, it made a substantial difference to her family's financial situation. However, it also determined her destiny as a high school dropout. She explained: "That's why I am not educated today. I want the best for my children because of what happened to me." Whereas middle-class parents might say to their child: "Look at me [my profession] and do what I have done to become successful," these mothers tell their children: "Look at me, I'm a cleaner because I dropped out of school and only completed one year of high school. I want you to complete your schooling because it will give you more options in life."

Ntombi, who worked as a tea-lady, wanted her son to see how hard she had to work to support her family. By doing so, she educated her son about the dignity of working for a living, and shared her work struggles as a way to discourage him from following in her footsteps. Barbara, who was in the process of obtaining the General Education and Training Certificate through an adult basic education programme, was modelling to her daughters the importance of investing in education. Through Yosso's (2005) lens, these are all examples of 
resistant capital that the mothers shared as life lessons with their adolescents to encourage them to complete their formal schooling. They were resisting the repeat of their own histories in their children's lives. The practices of the mothers can also be described as aspirational capital because they sought to "maintain hopes and dreams for the future . . . and nurture a culture of possibility" (Yosso, 2005, p. 78). This message of valuing education was also reflected in the artefacts on display in their homes. Beth had a wall dedicated to displaying all her children's certificates. Similarly, in Evelyn's home, what caught the eye were three framed photographs. One showed Evelyn with a certificate she had received for a short course, the other two were school photos of her children. We interpreted these as examples of how the mothers surrounded their children with reminders of the importance of investing in education.

\section{"I always make a plan": Narratives of resistance, resourcefulness, and hope}

Patriarchy decentres women and positions them as subservient to men. This societal positioning disadvantages single-mother families in that these family units are viewed as incomplete and disadvantaged. Although these women were not openly challenging their inequality through political or social activism, they were trying to improve their current life situation. Their legacy of racialised oppression was visible in the poverty, unemployment, and unsafe community they described but, within that, the mothers' efforts to stand up to it is evident too.

One way to improve their financial circumstances was to exploit the shortage of housing in their poor township community and to sublet part of their plots to tenants. Ntombi had three, and Beth had two, additional rental structures on her plot. However, as women living in an unsafe community, they had to be vigilant about who they rented to and had to implement rules regarding visitors and the use of alcohol on the premises. Ulin supplemented the family income by trading in rice and other pulses. She bought pulses in large quantities, which she repackaged into smaller quantities to sell in the community. These examples from the data speak to their resiliency to survive by finding ways to supplement their families' income. These mothers' efforts to support their families were acknowledged by their children. Our analysis further shows that, through their actions, they were fostering an environment in which their adolescents could become resilient over time (Ungar et al., 2011).

Like all parents of adolescent children, these mothers were pressurised to buy them modern technological gadgets such as cell phones. Ulin told how she initially refused Tommy's request for an expensive cell phone. However, when he was placed on the top-ten list for his grade at school, she decided to celebrate his accomplishments by acquiescing his request for a cell phone. Similarly, Ntombi tied her buying of gifts for Calvin to his having earned it. Both Ntombi and Ulin's expensive purchases for their sons could easily be interpreted as inappropriate and extravagant gestures for poor and unemployed mothers. But they were investing aspirational capital in their sons with the message that doing well at school leads to better dividends in later life. 
An important support practice the mothers engaged in was daily dialogues with their adolescent children. These conversations mostly focussed on two themes: being vigilant, and being actively engaged with their schoolwork. Their actions stemmed from a common concern about the danger of living in a community in which gangsterism and school dropout were rife, and the potential negative influence this could have on their children's futures. They had no illusions about the negative influences of drugs and gangsterism that Western Cape township boys fall prey to. They constantly held up the negative behaviour of other youth in the community as examples of negative influences on educational success, and strongly discouraged their sons from forming friendships with high school dropouts.

The mothers wanted their children to dream of a better life, and to not accept the lives they were leading as their destiny. Therefore, they used their own lives as examples of how incomplete schooling and the lack of qualifications limited career options in life. Their conversations with their adolescent children were often about career aspirations and career choices. Although Ulin's high school education stopped when she fell pregnant and dropped out of school, Tommy knew she had dreamed of becoming an attorney. She wanted Tommy's dream of becoming a mechanical engineer to become a reality and encouraged him to succeed. Barbara continually reminded Palesa that, "without university training you will not get a good job." She used herself as an example when she encouraged Palesa to complete her schooling: "If you don't want to work in a kitchen like your mother then you must study to become something." This resistant and aspirational capital was carefully spent by mothers who believed that their children deserved the best, regardless of their family's financial circumstances. Beth's words echoed the belief all the mothers had when it came to supporting their children: "Through my situation, through everything that we have been through, I have always tried to give my children the best."

\section{"I pray for my child": Narratives of spirituality as support}

The mothers also drew on spirituality as an important form of support. Our analysis shows that spirituality performed several support functions and shaped the mothers' behaviours in ways that were supportive, too. Prayer was a common form of support and power in the families. The mothers seemed to believe that praying for their children's education was an important way in which they offered support to their children. They also taught their children how to use prayer as hope and perseverance, and to be involved in their church in a proactive way. They and their families participated in formalised religious practices such as the Sunday church service. These parents all involved their children in religious practices to accumulate capital to spend on their spiritual well-being, and some had success in advancing spirituality in their adolescents. Examples include Ntombi's son, Calvin's, commitment to participate in such rituals. According to her, he rose early on a Sunday to prepare for church without any prompting from her. Beth said that her son, Mikyle, sought support from a higher order when he wrote exams. She quoted him as saying, "Mommy, before I write my exam I say to the Lord: 'Lord, you know the answers, open my thoughts and my brain so that I can think clearly and answer the questions." These examples highlight the ways in which the children used religious rituals and spiritual practices as capital to navigate their own challenges. 
The church was a support they leaned on to cope with their daily struggles. They described how, in difficult times, they drew strength and comfort from their belief system and used prayer and faith as source of strength and hope. Other church members mitigated the experiences of depression and hopelessness that Mandy experienced. She said, "If it seems as though I am becoming weak or despondent, then they will always tell me, 'But you have come so far and nothing bad happened to you. The Lord has always been there."”

Both Mandy and Barbara said they would not have survived without the support the church provided in their times of need. Barbara spoke about the emotional support church members provided when her family was struggling, and recalled the help she received when her family was destitute and she could not feed her children. She had had no choice but to disclose her family's situation to the priest. She found support in the church community and church members turned up with material resources and food parcels for her family. Barbara believed it was her faith that God would help her "through good times and bad times," that gave her the confidence and courage to raise her children on her own. Their narratives show that spirituality was a form of capital that the parents saved for times of difficulty as well as for moments of joy. Spirituality, like resilience, was collectively accumulated in the mother-child dyads to establish an enabling environment.

\section{"Your child is my child and my child is your child": Family and community support networks}

From existing research, it seems that a common assumption about the single-parent household is that the parent is the sole supporter and provider for the child (HampdenThompson, 2013; Knowles \& Holmström, 2013). Our study refutes this viewpoint because these single mothers had access to various support networks, and were not always shouldering responsibilities on their own. Their networks of support were situated in their families as well as in the community and involved, amongst others, grandparents, siblings, cousins, neighbours, and church members. We found a reciprocal helping culture in their families and community that encouraged a shared responsibility for children's schooling. So, for example, Evelyn's sister's two children lived with her during the school year to give them easier access to schooling opportunities. Evelyn's support to her sister's children was both an investment in them as well as an opportunity to accumulate familial capital that could benefit her own children's educational success. This finding validates Yosso's point about the "lessons of caring, coping and providing" and the "importance of maintaining a healthy connection to [one's] community [or family] and its resources" (2005, p. 79) when you live in economically disadvantaged communities.

In most of the families, grandparents were physically and mentally part of the family unit, and performed the very important roles of stand-in parents and co-parents. It is clear that the participants drew support from them to assist with raising their children. Ulin's parents lived with her, acted as co-parents, and often supervised the children's homework and school projects. In some cases, the grandparents' financial support was invaluable for the family's survival and well-being. According to Barbara, "Granny always helps." She would request a list of things they needed, which she would buy to send back with them. Social contact with 
extended family members was important because it provided the adolescents with guidance from role models other than their mothers, for example, Therren and Calvin had adult relatives in their lives who were university students and who helped them with information about access to higher educational institutions. The women all spoke of the support and advice that siblings, cousins, and community members gave to their children to keep them focussed on their schooling. When Therren's female cousin told her: "Don't take a boyfriend before your time . . . think about your future," she listened. She wanted to break with the norm of girls in the family dropping out of school due to pregnancy.

In addition to family support, these single-parent households also enjoyed support from community members such as neighbours. One of Mandy's neighbours, whose daughter had started high school the previous year, guided her with advice on how to prepare financially for her child's transition to high school. And one of Beth's friends with connections to a nongovernmental organisation that supports disabilities, sourced the special school shoes Mikyle needed because of his physical impairment. We found in our conversations with the adolescents, that social networking provided them with access to scarce resources such as computers and the internet, which their families did not have. Community members made their computers available to Therren, Tommy, Palesa, and Mikyle when they had to do research and needed electronic information to complete projects and assignments. Mikyle's neighbour sometimes conducted searches on his behalf and printed out the information. Described above, are examples of social networks that benefitted the adolescents' educational development, and that we present as examples of "instrumental and emotional support to navigate through society's institutions" (Yosso, 2005, p. 79).

These single mothers' children's access to education was mitigated by the informal acts and practices we present here. These acts and practices all facilitated educational access and inclusion even though such links are not necessarily acknowledged in educational discourse. We have presented the forms of support that the adolescents and their mothers had access to in their immediate families as well as beyond, and which Yosso (2005) referred to as familial capital. According to Yosso, "familial capital is nurtured by our 'extended family,' which may include immediate family (living or long passed on) as well as aunts, uncles and grandparents who we might consider part of our familia" (2005, p. 79). Support also included community members and sites such as schools and churches that are "form[s] of cultural wealth [that] engages a commitment to community wellbeing and expands the concept of family" (Yosso, 2005, p. 79).

\section{Discussion}

In this article, we have argued that a broader lens is needed in order to understand the ways parents contribute to their children's education. Our understanding of parental educational support is that it should be much more inclusive and broader than schools' understandings, which often only link certain parent activities to educational success, namely, homework support, physical presence at children's extramural activities, and participation at meetings and school functions (Green et al., 2007; Lemmer, 2007; Mncube, 2009). Educational 
research has often approached single-mother families from a deficit perspective, assuming that due to a lack of economic resources and poor education, these families are an educational disadvantage for children (Aragon, 2018; Baquendano-Lopez et al., 2013; HampdenThompson, 2009; Koh et al., 2017). Instead, our research builds on research that has highlighted the stories of marginalised parents who wanted to, and believed that they should, be involved in their children's educational journey (Camacho-Thompson et al., 2019; Daniels, 2017; Epstein, 2011; Hoover-Demsey et al., 2001; LeFevre \& Shaw, 2012; Okeke, 2014).

Our study of this low-socioeconomic community identified many economic and social challenges that could negatively influence children's educational pathways. One such constraint is money, which makes the family unit a very vulnerable space to function in, and required the mothers to resort to creative ways to supplement the family's financial resources. Their adolescents' narratives show that they were knowledgeable about their families' dire financial situation and were sensitive about not making unreasonable demands on their mothers. The mothers were resilient and intentional in their engagement with educational support practices because they valued education and saw it as a vehicle to empower their children. They support our earlier research of mothers as "involved parents who are engaging with education as an investment in their children's futures" (Daniels, 2017, p. 6) despite their personal and social challenges.

In all the participating families, a healthy, respectful relationship existed between each parent and her adolescent child. We found that the mothers considered communication an important part of their investment in their children and a tool to counter the negative influences of community gangsterism and teenage pregnancy on adolescents' educational pathways. They used their own life stories, and experiences of their own interrupted schooling, to foster academic aspirations and to encourage their adolescents to invest in their education. They wanted their children to be educated because they connected education to a better life and advancement in society.

These findings build on international research that has shown that academic socialisation in low SES families often centred on stories from parents' own past and acts as examples of what not to do if you want to become successful in life (Lopez et al., 2001; Vega et al., 2015). These mothers' use of personal stories as encouragement, and their informal, day-to-day conversations with their adolescents, is referred to in the literature as academic socialisation (Bhargava \& Witherspoon, 2015; Hill \& Tyson, 2009; LeFevre \& Shaw, 2012). Their daily talks about the importance of education motivated their school-going children to work hard and not give up on their schooling. Such conversations are examples of academic socialisation of the children and, through care and support, the mothers built aspirational and resistant capital in their children, which was an investment in their children's educational journey.

This study further identified spirituality as a contributing factor to the quality of the motheradolescent relationship, and advanced intrinsic religiousness among the adolescents as well as greater parental responsiveness to the adolescents' challenges. Our analysis of the family 
units' culture reflects families that live by strong religious values, such as faith in God, thankfulness, and perseverance despite difficult circumstances. It was further evident that the mothers' religiousness led to self-motivated religiousness in their children as well as a greater sense that they could do something about their children's challenges when they felt constrained in various ways.

We found in these single-parent households, that parent support was a community effort rather than an individual family unit effort. Due to their daily challenges and internal struggles, the parents were realistic about their limitations to provide the best possible educational support. Consequently, they identified significant adults such as grandparents and community members who could serve as co-parents and who could support their adolescent children's education. Collaborations with the extended family, neighbours, and teachers provided the adolescents with access to adult support and surrogate parent figures alongside their mothers. In this regard, the important role that grandparents play in supporting the single-mother family, and how they often step in as surrogate parents to share the responsibilities of parenting, was illuminated.

\section{Conclusion}

In this article, we sought to prioritise and foreground single-mother family units to afford them with an opportunity to tell their stories, and for a different grand narrative about singlemother households to emerge. We discussed how the six single-mother families in this study employed various nontraditional or unacknowledged forms of educational support. The parents, Barbara, Evelyn, Ulin, Beth, Mandy, and Ntombi, accumulated community cultural wealth in the forms of familial, social, aspirational, spiritual, resistant, and navigational capital, and used it in the service of their children's educational trajectory. As single parents facing challenges with supporting their children effectively, they established social networks of support external to their family units to scaffold the challenges their children came up against in society.

The findings suggest that it is counterproductive to engage with single-mother families as broken or incomplete family units simply because the father parent is absent from the family. Single-parent families are the norm in society, not the exception. A broader conceptualisation of educational support by society, especially the educational sector, is recommended. It is for this reason that research and critical dialogue about the social construction of single-mother families and their engagement with education is important. Educational research that could inform society how these parents support their children's educational pathways continues, however, to be limited. In the process, educational environments remain uninformed about the strengths and the creative ways in which such family units operate to provide the best educational opportunities for their children. Relevant educational research could inform schools about the unique needs for support that such family units have, and the type of support that such students can benefit from. 
Our findings have implications for home-school partnerships and collaborations. Recognition of the informal and nontraditional forms of capital that are present in single-mother families is important when schools seek to collaborate with parents. Intervention home programmes for adolescents should take into consideration surrogate parent support structures and the role that co-parenting plays in the lives of adolescents. Thus, instead of focusing on the assumed roles of fathers, rather list parents' responsibilities and how best the family unit can respond to them. This will allow other strategic family and community role-players in the adolescents' environment to step in and support the adolescent in meaningful ways.

\section{References}

Aragon, A. (2018). Achieving Latina students: Aspirational counter stories and critical reflections on parental community cultural wealth. Journal of Latinos and Education, 17(4), 373-385.

Baquendano-Lopez, P., Alexander, R. A., \& Hernandez, S. J. (2013). Equity issues in parental and community involvement in schools: What teacher educators need to know. Review of Research in Education, 37, 149-182.

Bhargava, S., \& Witherspoon, D. P. (2015). Parental involvement across middle and high school: Exploring contributions of individual and neighborhood characteristics. Journal of Youth and Adolescence, 44(9), 1702-1719.

Bourdieu, P. (2007). Forms of capital. In A. R. Sadovnik (Ed.), Sociology of education: A critical reader. New York.

Budlender, D., \& Lund, F. (2011). South Africa: A legacy of family disruption. Development and Change, 42(4), 925-946.

Camacho-Thompson, D. E., Gonzalez, N. A., \& Fuligni, A. J. (2019). Adolescent academic socialization: A within-group comparative analysis among Mexican-origin families. Journal of Adolescent Research, 34(4), 411-437.

Creswell, J. W. (2007). Qualitative enquiry and research design: Choosing among five approaches. SAGE.

Daniels, D. (2017). Initiating a different story about immigrant Somali parents' support of their primary school children's education. South African Journal of Childhood Education, 7(1), 1-8.

Daniels, D. (2018) Educating in diverse worlds: The immigrant Somali parent as a strategic partner of South African education. In E. Walton \& R. Osman (Eds.), Teacher education for diversity: Conversations from the Global South (pp. 87-102). Routledge. 
Epstein, J. (2011). School, family, and community partnerships, student economy edition: Preparing educators and improving schools. Westview Press.

Epstein, J. (2018). School, family, and community partnerships, student economy edition: Preparing educators and improving schools (2nd ed.). Routledge.

Gagnon, J. D. (2018). "Bastard" daughters in the ivory tower: Illegitimacy and the higher education experiences of the daughters of single mothers in the UK. Teaching in Higher Education, 23(5), 563-575.

Green, C. L., Walker, J. M., Hoover-Dempsey, K. V., \& Sandler, H. M. (2007). Parents' motivations for involvement in children's education: An empirical test of a theoretical model of parental involvement. Journal of Educational Psychology, 99(3), 532-544.

Hampden-Thompson, G. (2009). Are two better than one? A comparative study of achievement gaps and family structure. Compare, 39(4), 517-534.

Hampden-Thompson, G., \& Galindo, C. (2015). Family structure instability and the educational persistence of young people in England. British Educational Research Journal, 41(5), 749-766.

Hill, N. E., \& Tyson, D. F. (2009). Parental involvement in middle school: A meta-analytic assessment of the strategies that promote achievement. Developmental Psychology, 45(3), 740-763.

Hoover-Dempsey, K. V., Battiato, A. C., Walker, J. M., Reed, R. P., DeJong, J. M., \& Jones, K. P. (2001). Parental involvement in homework. Educational Psychologist, 36(3), 195-209.

Hoover-Dempsey, K. V., \& Sandler, H. M. (1997). Why do parents become involved in their children's education? Review of Educational Research, 67(1), 3-42. Jacobs, C. (2019). Parental educational support for adolescents in single-mother families of a low-income community [Unpublished doctoral dissertation]. Stellenbosch University, South Africa.

Jeynes, W. H. (2011). Parental involvement research: Moving to the next level. School Community Journal, 21(1), 9-18.

Kaplan Toren, N. (2013). Multiple dimensions of parental involvement and its links to young adolescent self-evaluation and academic achievement. Psychology in the Schools, $50(6), 634-649$.

Knowles, G., \& Holmström, R. (2013). Understanding family diversity and home-school relations: A guide for students and practitioners in early years and primary settings. Routledge. 
Koh, E., Stauss, K., Coustaut, C., \& Forrest, C. (2017). Generational impact of single-parent scholarships: Educational achievement of children in single-parent families. Journal of Family Issues, 38(5), 607-632.

LeFevre, A. L., \& Shaw, T. V. (2012). Latino parent involvement and school success: Longitudinal effects of formal and informal support. Education and Urban Society, 44(6), 707-723.

Lemmer, E. M. (2007). Parent involvement in teacher education in South Africa. International Journal About Parents in Education, 1, 218-229.

Lopez, G. R., Scribner, J. D., \& Mahitivanichcha, K. (2001). Redefining parental involvement: Lessons from high-performing migrant-impacted schools. American Educational Research Journal, 38(2), 253-288.

Merriam, S. B. (2009). Qualitative research: A guide to design and implementation. JosseyBass.

Mncube, V. (2009). The perceptions of parents of their role in the democratic governance of schools in South Africa: Are they on board? South African Journal of Education, 29, 83-103.

Musick, K., \& Meier, A. (2010). Are both parents always better than one? Parental conflict and young adult well-being. Social Science Research, 39(5), 814-830.

Newlin, M. (2017). Public perceptions towards children brought up by single mothers: A case of Queenstown, South Africa. Journal of Human Ecology, 58(3), 169-180.

Okeke, C. I. O. (2014). Effective home-school partnership: Some strategies to help strengthen parental involvement. South African Journal of Education, 34(3), 1-9.

Patton, M. (2002). Qualitative research and evaluation methods (3rd ed.). SAGE.

Rawatlal, N., Pillay, B. J., \& Kliewer, W. (2015). Socioeconomic status, family-related variables, and caregiver-adolescent attachment. South African Journal of Psychology, 45(4), 551-563.

Robinson, Q. L., \& Werblow, J. (2012). Beating the odds: How single black mothers influence the educational success of their sons enrolled in failing schools. American Secondary Education, 40(2), 52-66.

Seginer, R. (2006). Parents' educational involvement: A developmental ecology perspective. Parenting: Science and Practice, 6(1), 1-48.

Toren, N. K., \& Seginer, R. (2015). Classroom climate, parental educational involvement, and student school functioning in early adolescence: A longitudinal study. Social Psychology of Education, 18(4), 811-827. 
Ungar, M., Theron, L., \& Didkowsky, N. (2011). Adolescents' precocious and developmentally appropriate contributions to their families' well-being and resilience in five countries. Family Relations, 60(2), 231-246.

Vega, D., Moore, J. L., \& Miranda, A. H. (2015). In their own words: Perceived barriers to achievement by African American and Latino high school students. American Secondary Education, 43(3), 36-59.

Wang, M., \& Sheikh-Khalil, S. (2014). Does parental involvement matter for student achievement and mental health in high school? Child Development, 85(2), 610-625.

Williams, T. T., \& Sánchez, B. (2012). Parental involvement (and uninvolvement) at an inner-city high school. Urban Education, 47(3), 625-652.

Yosso, T. J. (2005). Whose culture has capital? A critical race theory discussion of community cultural wealth. Race Ethnicity and Education, 8(1), 69-91. 